\title{
Presynaptic Transmitters and Depolarizing Influences Regulate Development of the Substantia Nigra in Culture
}

\author{
Wilma J. Friedman, ${ }^{1,2, a}$ Cheryl F. Dreyfus, ${ }^{1}$ Bruce McEwen, ${ }^{2}$ and Ira B. Black ${ }^{1}$ \\ ${ }^{1}$ Division of Developmental Neurology, Department of Neurology, Cornell University Medical College, New York, \\ New York 10021, and ${ }^{2}$ Rockefeller University, New York, New York 10021
}

\begin{abstract}
Recent evidence suggests that extracellular signals regulate neurotransmitter traits in brain catecholaminergic (CA) neurons as in the periphery. Development of the dopaminergic phenotype in the mouse substantia nigra (SN) was studied by monitoring tyrosine hydroxylase (TH), the rate-limiting enzyme in CA biosynthesis in vivo and in culture. Explants of SN were dissected from embryonic day 15 embryos and grown in culture for a week. To define the influence of depolarizing signals on central dopaminergic neurons, cultures were grown with the pharmacologic depolarizing agent veratridine. This treatment elicited a significant increase in TH enzyme activity, accompanied by elevated levels of enzyme protein. The increase in activity was prevented by TTX, suggesting that transmembrane $\mathrm{Na}^{+}$influx was necessary for the rise in TH. A physiologic presynaptic agonist, substance $P$, also evoked a significant increase in TH activity; however, the coproduced tachykinin peptide, substance K (SK, neurokinin $A$ ) elicited a more dramatic rise. The SK effect was blocked by TTX, suggesting that the physiologic agonist was acting through the same mechanism as the pharmacologic agent veratridine. Immunoblot analysis revealed that SK elicited a parallel increase in TH enzyme protein. Our observations suggest that the novel peptide, SK, serves a physiological role in the regulation of $\mathrm{TH}$ in the striatonigral pathway.
\end{abstract}

While extensive evidence indicates that epigenetic signals regulate peripheral neuronal function during development and maturity, the role of environmental signals in brain development is poorly understood. Our present studies were designed to examine environmental mechanisms influencing brain ontogeny.

In the PNS, neurotransmitter phenotypic expression and development are regulated by a variety of epigenetic signals (Dibner and Black, 1976; Black, 1978; Patterson, 1978; Black and Patterson, 1980; Bohn, 1983; Doupe et al., 1985). Transmitter

\footnotetext{
Received July 7, 1987; revised Mar. 7, 1988; accepted Mar. 24, 1988.

We gratefully acknowledge Dr. Joe Nevins of the Rockefeller University for expert advice and assistance in the immunoblot technique. We also thank Marlene Gillies and Daxa Patel for excellent technical assistance and Bettye Mayer for secretarial assistance. Antibody to tyrosine hydroxylase used in this work was generously provided by Dr. Keith Markey. This study was supported by NIH Grants NS 20788, NS 10259, HD and NIH Institutional NRSA T32GMO7524, and The American Parkinson's Disease Foundation. C.F.D. is the recipient of a Teacher Scientist Award from the Andrew W. Mellon Foundation. I.B.B. is a recipient of a McKnight Research Project Award.

Correspondence should be addressed to Dr. Cheryl F. Dreyfus, Division of Developmental Neurology, Cornell University Medical College, 515 East 71st Street, New York, NY 10021.

a Present address: Zoology Department, Uppsala University, Box 561, S-75122, Uppsala, Sweden.
}

Copyright (C) 1988 Society for Neuroscience $0270-6474 / 88 / 103616-08 \$ 02.00 / 0$ phenotypes have been examined using specific markers such as biosynthetic enzymes and high-affinity transmitter uptake systems. In sympathetic neurons in vivo, normal ontogeny of tyrosine hydroxylase (TH), the rate-limiting enzyme in catecholamine biosynthesis (Levitt et al., 1965; Udenfriend, 1966), is dependent upon transsynaptic stimulation with attendant depolarization (Black et al., 1971; Thoenen, 1974). Similarly, TH is regulated by pharmacologic depolarization of sympathetic neurons in culture (Walicke et al.,1977; Hefti et al., 1982). Thus, membrane depolarization apparently influences development and function of peripheral catecholaminergic (CA) neurons. It remains unclear, however, whether similar mechanisms govern neurotransmitter expression in brain catecholaminergic neurons.

Regulatory events underlying CNS development remain obscure due, in part, to the extreme complexity and relative inaccessibility of the brain. Nevertheless, specific histochemical and biochemical markers have been used to examine the ontogeny of different neuronal populations (Coyle and Axelrod, 1972; Olson and Seiger, 1972; Coyle et al., 1973; Lauder and Bloom, 1974; Schlumpf et al., 1977; Specht et al., 1981a-c; Berger et al., 1982; Kotake et al., 1982; Verney et al., 1982; Dreyfus et al., 1986). However, specific signals governing ontogeny are largely unknown. We are employing culture techniques to manipulate the environment of CNS neurons to elucidate the role of specific epigenetic cues in brain development (Dreyfus et al., 1979, 1980, 1983, 1986).

In particular, we have studied the development of dopaminergic phenotypic traits in the mouse ventral mesencephalon. The mesencephalic substantia nigra (SN) contains the largest population of dopamincrgic ncurons in the brain, cxpressing markers, such as $\mathrm{TH}$, that can be used to monitor development in vivo and in vitro. Nigral neurons project rostrally to innervate the striatum, limbic system, and neocortex (Anden et al., 1966; Fuxe et al., 1974; Fallon et al., 1978; Specht et al., 1981c). Normal function of the nigrostriatal dopaminergic neurons is necessary for basic motor activities such as coordination and balance.

In the present study we have examined the ontogeny of $\mathrm{TH}$ in vivo and in explant culture. Our observations indicate that the normal presynaptic excitatory transmitters regulate the number of $\mathrm{TH}$ molecules in nigral neurons. These studies begin to define the role of specific environmental signals on neuron maturation in the CNS.

\section{Materials and Methods}

Culture methods. CD-1 mice (Charles River Co.) were used for all experiments. Embryonic age was calculated from the day of discovery of 


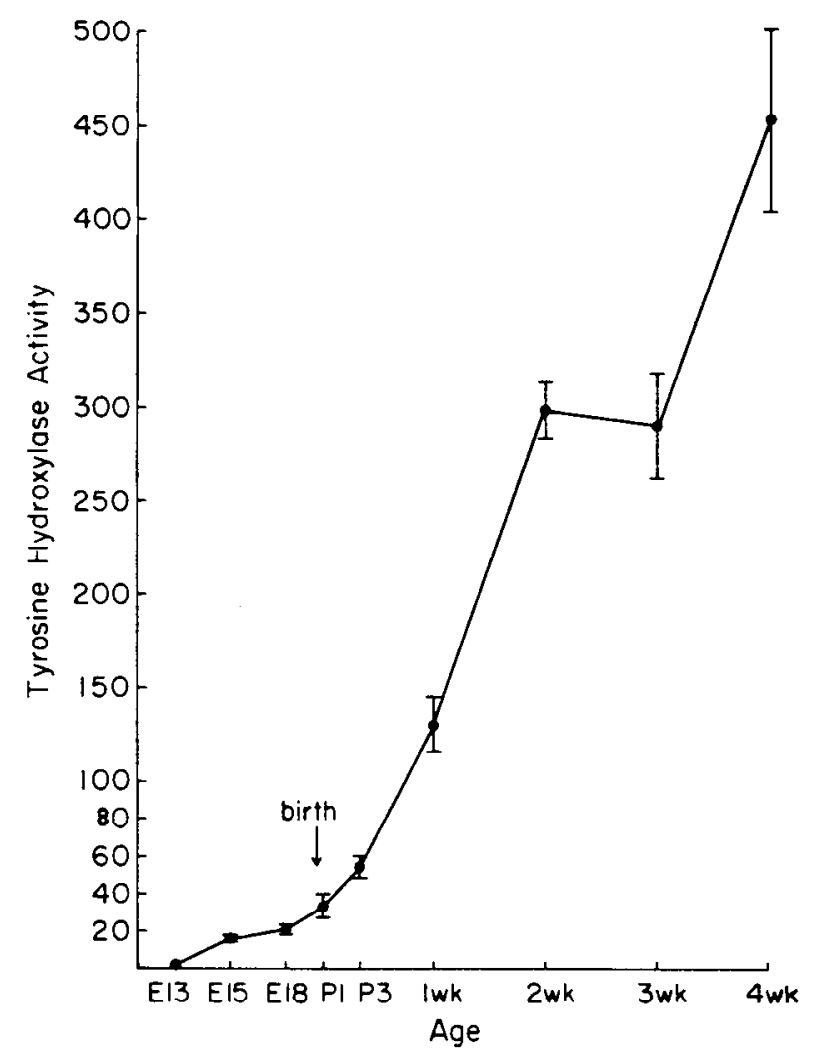

Figure 1. In vivo development of tyrosine hydroxylase activity in SN. TH activity is expressed as mean pmoles DOPA produced per SN per hour $( \pm$ SEM). Age refers to embryonic $(E)$ or postnatal $(P)$ day or week (wk) on which tissue was assayed. $n=16$ independent samples per point.

the vaginal plug, which was designated Day 1. Pregnant mice were killed on the appropriate developmental day. Fetuses were removed and placed on ice. Under a dissecting microscope, the ventral mesencephalon, including the $\mathrm{SN}$, was explanted and maintained in organotypic tissue cultures for varying periods of time (Bornstein, 1973; Dreyfus et al., $1979,1980,1983,1986)$.

Explants were placed on photoreconstituted collagen-coated coverslips (Masurovsky and Peterson, 1973) and maintained in Maximow depression slide chambers at $34.5^{\circ} \mathrm{C}$. Nutrient medium, which was renewed twice weekly, consisted of rat serum (33\%), Eagle's minimal essential medium ( $50 \%$ ), chick embryo extract $(10 \%)$, glucose $(600 \mathrm{mg} \%)$, and achromycin with ascorbic acid $(1.2 \mu \mathrm{g} / \mathrm{ml})$. The SN from one side of the brain served as a control for experimental manipulation of the other. All groups within individual experiments were grown under identical conditions, using the same batch of collagen substrate and the same batch of nutrient medium; only drugs or vehicle differed.

Drug treatments. Optimal doses for the depolarizing agents veratridine (Sigma), substance P (SP; pGlu ${ }^{5}, \mathrm{MePhe}^{8}$, Sar; ; Peninsula Labs), and substance $\mathrm{K}$ (SK; neurokinin A; Peninsula $\mathrm{I}$ abs) were determined from dose-response experiments. Concentrations of veratridine ranging from $15 \mathrm{nM}$ to $15 \mu \mathrm{M}$ were examined. Concentrations of SP and SK ranged from $1 \mathrm{~nm}$ to $1 \mu \mathrm{M}$. TTX (Sigma) was used at $0.1 \mu \mathrm{M}$, which was found to be sufficient to block the effect of veratridine. SK was used in the presence of the peptidase inhibitors bacitracin (Sigma, $2 \mathrm{mg} / \mathrm{ml}$ ) and captopril (2 mm) to prevent breakdown of the peptide.

TH assay. After varying periods of time, cultures were rinsed in cold Hanks' balanced salt solution (HBSS) and dissected from the collagencoated coverslips. Each SN culture was placed in a conical test tube containing $10 \mu \mathrm{l}$ of ice-cold distilled water. For the in vivo development of TH, pregnant mothers, or the young mice, were sacrificed on the appropriate day, and the nigra was dissected and transferred to conical test tubes containing $10 \mu \mathrm{l}$ cold distilled water. The tissue was homogenized with a flame-blunted pipet and assayed for TH activity according to published procedures (Black, 1975). Samples were counted in a Packard liquid scintillation counter.

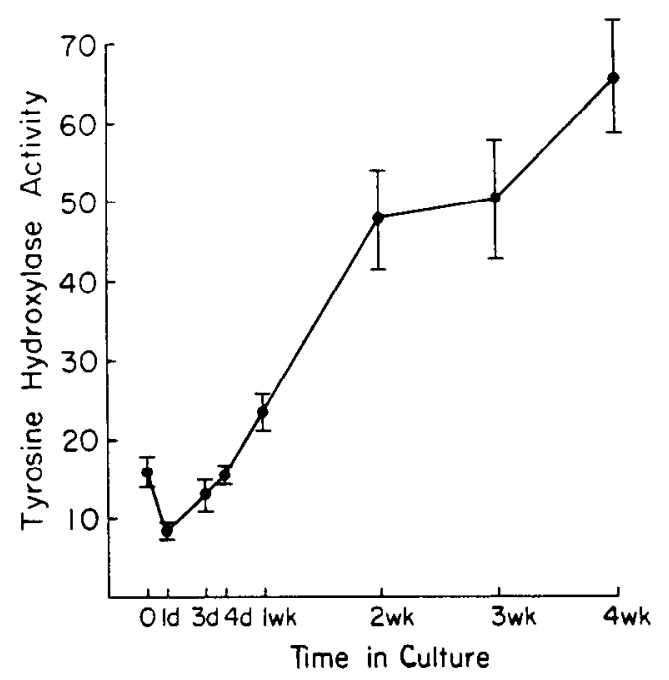

Figure 2. Development of TH activity in cultures of SN. TH activity is expressed as in Figure 1. $n=18$ cultures per point.

Immunocytochemistry. Cells containing $\mathrm{TH}$ were visualized using a modification (Dreyfus et al., 1983, 1986) of the immunocytochemical technique described by Berod et al. (1981). Cryostat sections $(10 \mu \mathrm{m})$ were stained with a specific antiserum against rat pheochromocytoma TH prepared in rabbit (Markey et al., 1980) and visualized with fluorescein-conjugated anti-rabbit IgG. Tissue was examined using a fluorescence microscope with incident illumination (Ploem) and a $200 \mathrm{~W}$ mercury lamp combincd with a Lcitz " $H$ " cubc. Photomicrographs wcrc taken with a Leitz Orthomat camera using high-speed Ektachrome film. Control cultures were treated identically except for the substitution of preimmune serum for the TH antiserum.

Western blots. Relative amounts of TH enzyme protein in cultures subjected to different drug treatments were determined by immunoblot analysis (Feldman et al., 1982). Cultures were homogenized in water, and aliquots were assayed for total protein concentration (Bradford, 1976). Equal amounts of protein from the different samples were added to a gel sample buffer containing Tris- $\mathrm{HCl}, 0.125 \mathrm{M}, \mathrm{pH} 6.8 ; 5 \%$ 2 -mercaptoethanol, and $3 \%$ SDS and heated to $100^{\circ} \mathrm{C}$ for $3 \mathrm{~min}$. The samples were loaded on a $10 \%$ acrylamide-SDS gel and separated by electrophoresis. Proteins were transferred electrophoretically to nitrocellulose (Towbin et al., 1979) in a buffer containing Tris base, $3 \mathrm{gm} /$ liter; glycine $14.4 \mathrm{gm} / \mathrm{liter}$; and $20 \%$ methanol. After transfer, the nitrocellulose membrane was incubated in RIPA buffer (Tris- $\mathrm{HCl}, 0.05$ $\mathrm{M}, \mathrm{pH} 7.4 ; \mathrm{NaCl}, 0.15 \mathrm{M} ; 1 \%$ Triton $\mathrm{X}-100 ; 1 \%$ sodium deoxycholate; $0.1 \%$ SDS) with $0.5 \% \mathrm{BSA}$ for $30 \mathrm{~min}$. The blot was exposed to $20 \mu \mathrm{l}$ TH antiserum in $15 \mathrm{ml}$ RIPA buffer for $3 \mathrm{hr}$. The bound antibody was detected by incubating the blot with ${ }^{125}$ I-staphylococcal protein A (New England Nuclear) for $1 \mathrm{hr}$. The nitrocellulose membrane was washed several times in RIPA buffer and $0.05 \mathrm{~m}$ Tris- $\mathrm{HCl}, \mathrm{pH} 7.4$, and exposed to X-ray film to detect radioactivity. The radioactive bands on the film were analyzed densitometrically (Helena Laboratories Densitometer) to assess relative levels of immunoreactive TH protein.

Binding of TH antibody in the Western blot exhibited linearity in the range of $12.5-150 \mu \mathrm{g}$ total protein. In our experiments, $50 \mu \mathrm{g}$ total protein was routinely used for each sample.

Statistical analysis. Data were analyzed by Student's $t$ test or by analysis of variance followed by Newman-Keuls test, as appropriate.

\section{Results}

\section{TH development in vivo}

TH cnzyme activity was initially cxamincd in vivo to definc normal development in the $\mathrm{SN}$. Using a sensitive catalytic assay, TH was first detected on embryonic day (E) 13 (Fig. 1), after which there was a 15-fold increase during embryonic life. TH activity continued to rise sharply after birth, exhibiting a 10 fold rise during the first 2 postnatal weeks. There was a more gradual increase thereafter until 4 weeks, the oldest age studied. 


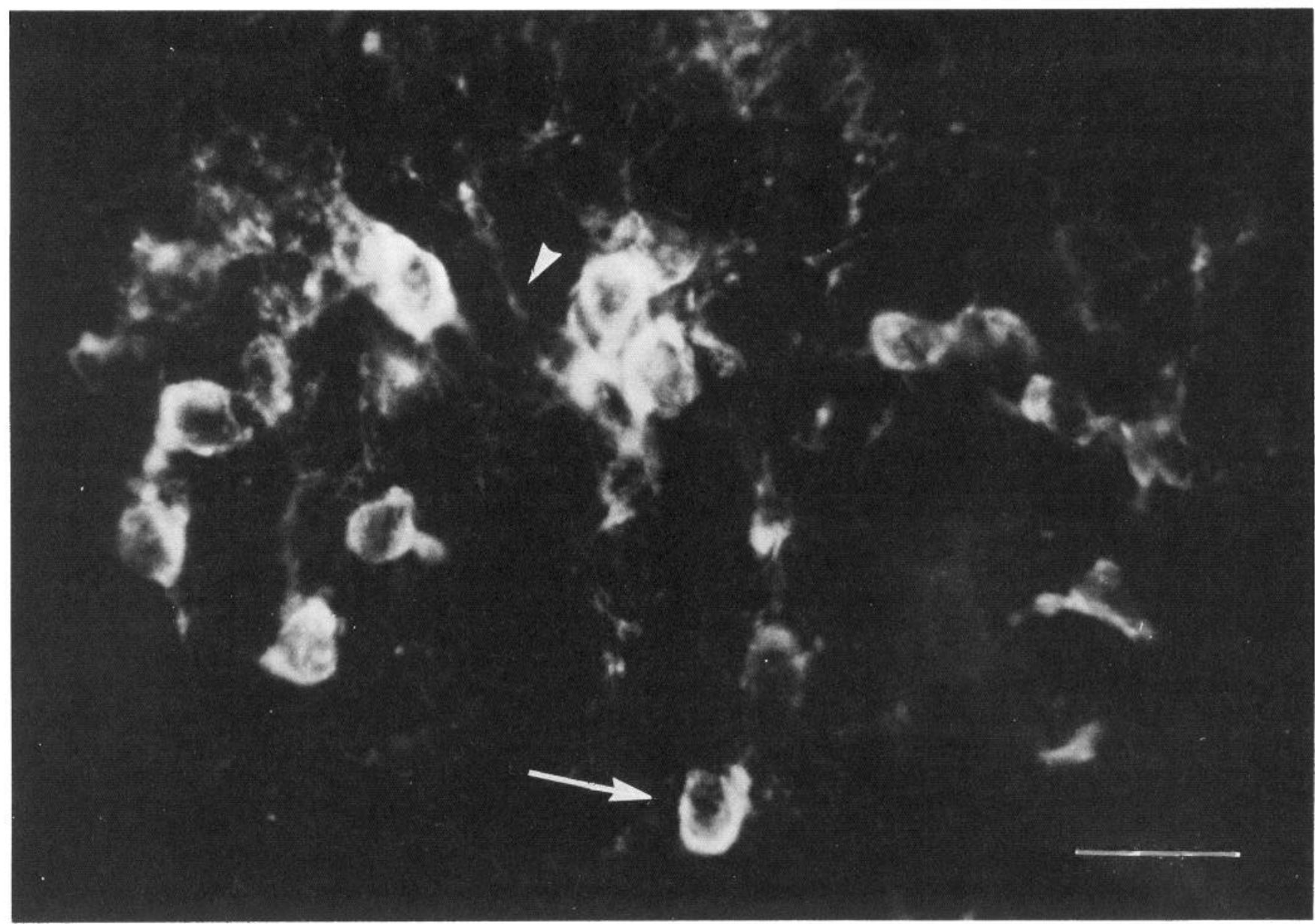

Figure 3. Immunocytochemical labeling of TH in a 2 week culture of E15 SN. TH is visualized with an anti-TH antibody and a fluoresceinlabeled secondary antibody. Arrow indicates positively stained cytoplasm surrounding negatively stained nucleus. Arrowheads denote a TH-positive process. Scale bar, $30 \mu \mathrm{m}$.

\section{Development of dopaminergic neurons in culture}

To examine the regulation of $\mathrm{TH}$ development, the $\mathrm{SN}$ was grown in an easily manipulated tissue culture environment. Explants were dissected from E15 embryos. During the first day

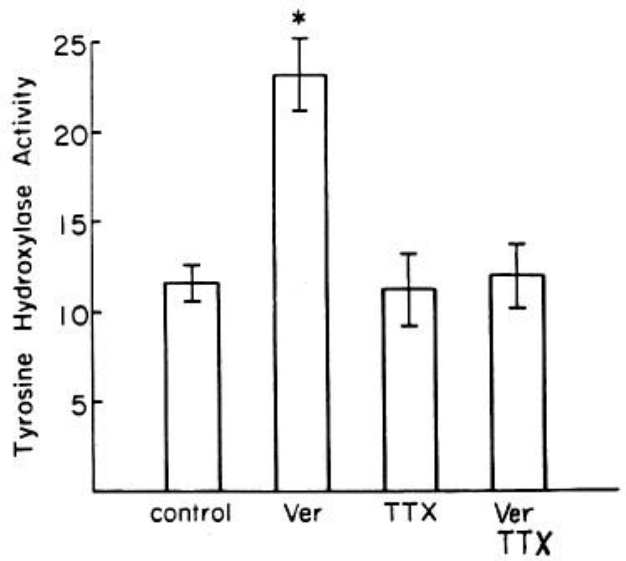

Figure 4. Effect of veratridine $(1.5 \mu \mathrm{M})$ and/or TTX $(0.1 \mu \mathrm{M})$ on TH activity in 1 week cultures of E15 SN. TH activity is expressed as in Figure $1 . n=16$ cultures per group. Asterisk indicates that analysis of variance revealed the veratridine group differed from all other groups at $p<0.001$. The other groups did not differ significantly from each other. in culture there was a decrease in $\mathrm{TH}$ activity, possibly due to trauma to the tissue. Subsequently, however, TH activity exhibited a marked, 8 -fold increase in nigra cultures over 4 weeks (Fig. 2).

Immunocytochemical procedures were employed to define the cellular localization of TH and to examine morphology of TH-positive cells (Berod et al., 1981; Dreyfus et al., 1983). Explants were stained with antiserum directed against TH (Markey et al., 1980) and were visualized with a fluorescein-labeled secondary antibody (Fig. 3). TH-immunoreactive protein was localized to the cytoplasm of cells approximately $14 \mu \mathrm{m}$ in diameter. Large, negatively stained nuclei with diameters of approximately $7 \mu \mathrm{m}$ were apparent. Positively stained processes, emanating from cell bodies, ramified throughout the explant.

\section{Effect of depolarizing agents on TH development}

Effect of veratridine on TH. To ascertain whether specific environmental cues play a role in the development of dopaminergic brain neurons, $\mathrm{SN}$ cultures were chronically exposed to the depolarizing agent veratridine for $7 \mathrm{~d}$. Veratridine binds to sodium channels eliciting ion influx, resulting in membrane depolarization (Ohta et al., 1973; Couraud et al., 1986). Exposure to the agent elicited a dramatic 2 -fold increase in TH activity (Fig. 4), suggesting that a pharmacologic depolarizing agent can regulate $\mathrm{TH}$ activity in culture.

To determine whether the rise in $\mathrm{TH}$ activity was specifically 


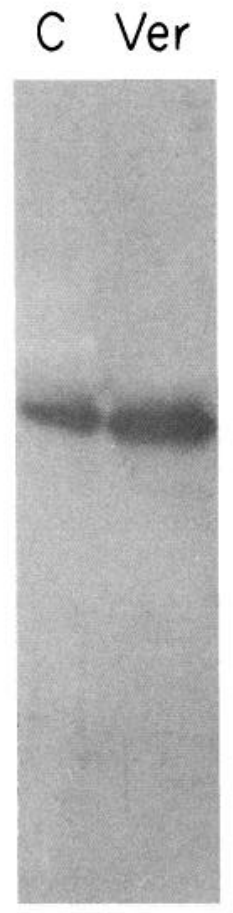

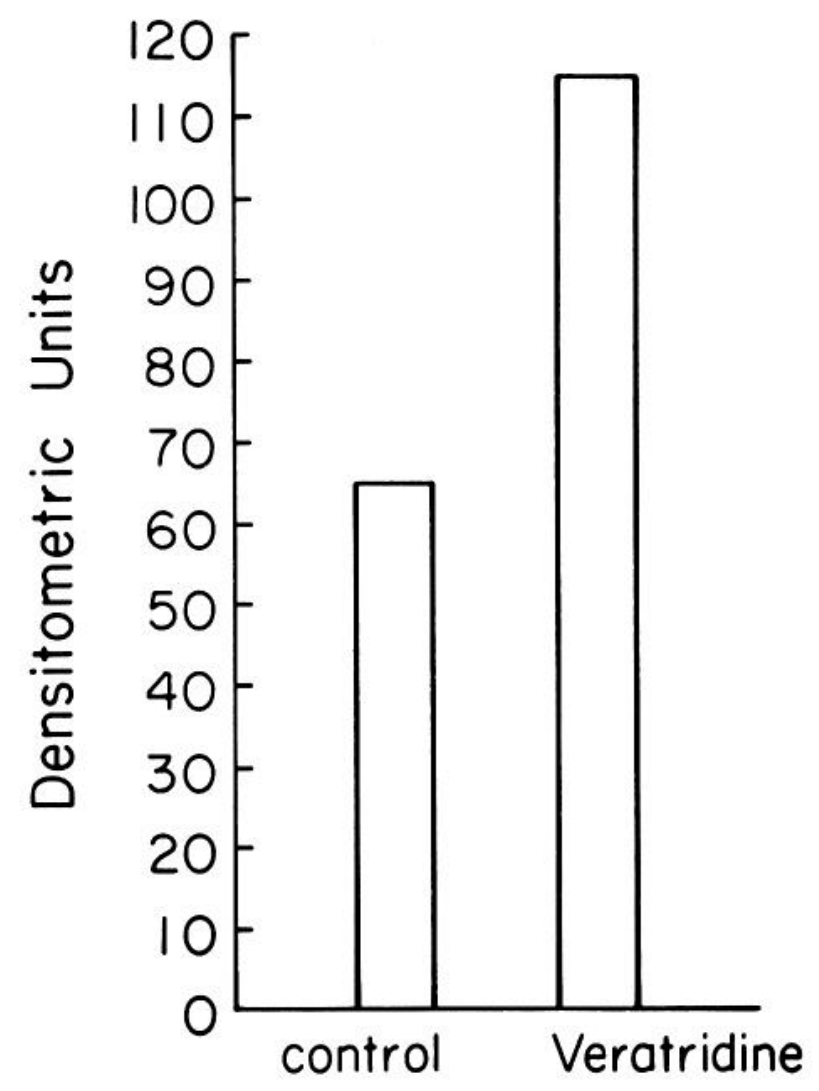

Figure 5. Western blot of E15 SN cultures grown for 1 week with or without $1.5 \mu \mathrm{M}$ veratridine. $C$, control; $\mathrm{Ver}$, veratridine. TH was visualized using a specific antiserum followed by labeling with ${ }^{125}$ I-protein A. Densitometry is expressed in arbitrary densitometric units. due to sodium influx attendant to depolarization, cultures were grown with TTX which blocks sodium channels (Kao, 1966). TTX prevented the veratridine-stimulated increase in TH activity (Fig. 4), indicating that the elevated enzyme activity was associated with sodium influx. TTX alone had no effect on TH activity.

To ascertain whether the veratridine-induced increase in $\mathrm{TH}$ was due to activation of the enzyme or to an increase in enzyme molecule number, we used the Western blot technique to estimate relative levels of TH protein. Veratridine elicited a marked increase in $\mathrm{TH}$-immunoreactive protein in $\mathrm{SN}$ cultures grown for 1 week (Fig. 5). Densitometric analysis indicated that TH protein rose approximately 2 -fold, the same magnitude as the increase in $\mathrm{TH}$ activity elicited by veratridine, suggesting that the increase in TH activity was entirely attributable to elevated enzyme protein.

Effects of physiologic agonists. To determine whether physiologic depolarizing stimuli act in the same manner as veratridine, cultures were grown in the presence of a native presynaptic agonist. The excitatory transmitter SP (Innis et al., 1985; Shults et al., 1985) is present in the striatonigral pathway in vivo. Since SP is degraded by peptidases in the medium, nigral cultures were grown with the stable sarcosyl analog to examine its effect on the development of TH. The SP analog significantly increased TH activity by approximately $50 \%$ (Fig. 6), indicating that a physiologic stimulus elicits effects similar to pharmacologic agents.

SP is present in high concentrations in the striatonigral pathway and is thought to play a central functional role. However, the small number of SP binding sites in the nigra has confounded this hypothesis (Shults et al., 1982, 1985; Quirion et al., 1983, Mantyh et al., 1984). A structurally related peptide, SK (NKA), is produced from the same precursor, preprotachykinin (PPT; Nawa et al., 1984a, b). Consequently, SK, and not SP, may play a predominant physiological role in striatonigral function. To determine whether SK affects TH in cultures of the SN, explants were grown in medium supplemented with varying doses of this

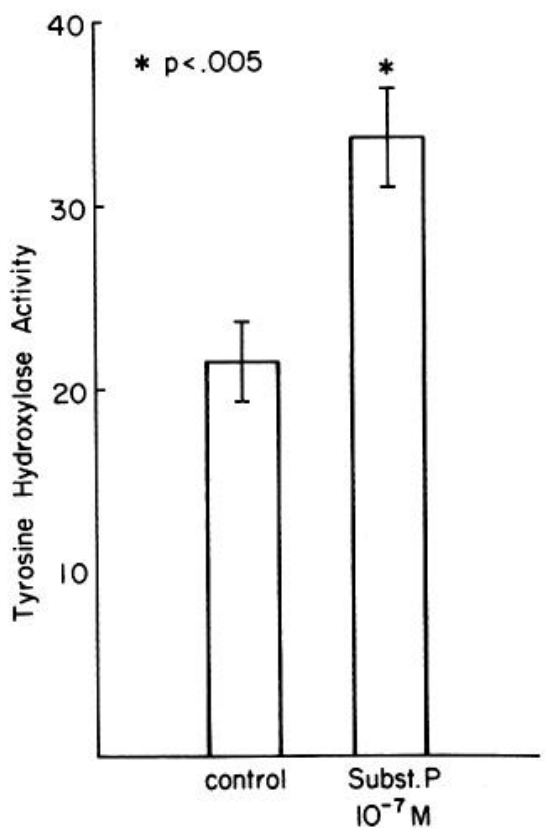

Figure 6. Effect of SP analog on TH activity in E15 SN cultures. Cultures were grown for 1 week with or without $0.1 \mu \mathrm{M}$ substance $\mathrm{P}$. Data is expressed as mean pmoles DOPA produced per culture per hour ( \pm SEM). $n=24$ cultures per group. ${ }^{*} p<0.05$ by Student's $t$ test. 


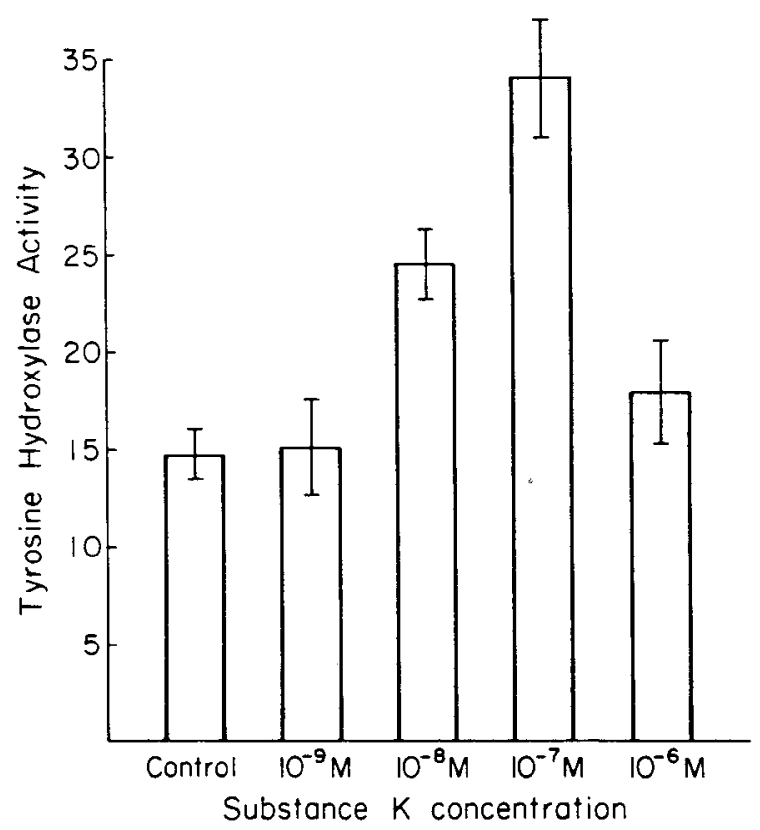

Figure 7. Dose-response curve showing the effect of substance $\mathrm{K}$ on TH activity in 1 week cultures of E15 SN. TH activity is expressed as in Figure 1. $n=12$ cultures per group.

presynaptic agonist (Fig. 7). In fact, SK elicited a greater than 2-fold increase in $\mathrm{TH}$ activity at the optimal dose.

To determine whether sodium influx was necessary for the SK effect, cultures were grown with TTX to block the sodium channels (Fig. 8). SN cultures grown with SK alone exhibited a 2 -fold increase in TH activity, and TTX completely blocked the rise, suggesting that the physiologic agonist elicited its effect via the same mechanism as the pharmacologic agent, veratridine.

To determine whether the SK stimulation of TH activity was mediated by an increase in enzyme protein, cultures were subjected to Western blot analysis (Fig. 9). SK treatment resulted in an approximately 2 -fold increase in $\mathrm{TH}$-immunoreactive protein, reflecting the magnitude of the increase in activity and reproducing the effect of pharmacologic depolarization.

\section{Discussion}

Numerous signals in the environment of developing cells may potentially modulate expression of specific traits. One class of stimuli, transsynaptic signals, regulates $\mathrm{TH}$, as well as other transmitter traits, in noradrenergic neuronal populations during development and maturity (Thoenen 1974; Walicke et al., 1977; Black, 1978; Patterson, 1978; Dreyfus et al., 1986). The present studies were designed to determine whether depolarizing stimuli regulate dopaminergic brain neurons and whether, consequently, this mode of regulation is widespread. We have found, in fact, that a population of brain dopaminergic neurons is similarly influenced by presynaptic cues. TH, in cultures of the $\mathrm{SN}$, is regulated by both pharmacologic and physiologic depolarizing stimuli. The increase in enzyme activity elicited by depolarizing signals is associated with increased enzyme protein, suggesting that presynaptic stimulation biochemically induces a critical neurotransmitter synthesizing enzyme.

\section{TH development in vivo}

Initial studies examined the development of $\mathrm{TH}$ in the $\mathrm{SN}$ in vivo. The normal ontogenetic profile of this marker provided

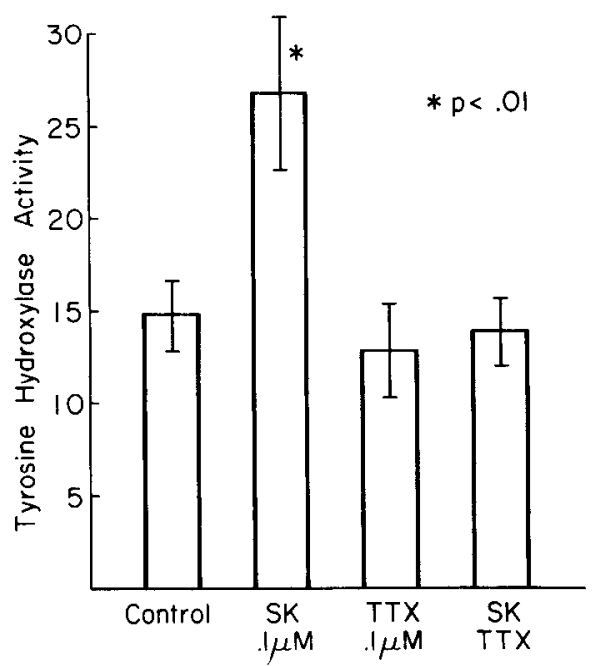

Figure 8. Effect of substance $\mathrm{K}(0.1 \mu \mathrm{M})$ and/or TTX $(0.1 \mu \mathrm{M})$ on TH activity in E15 SN cultures. TH activity is expressed as in Figure 1. $n$ $=12$ cultures per group. Asterisk indicates that analysis of variance revealed the substance $\mathrm{K}$ group differed from all other groups at $p<$ 0.01 . The other groups did not differ significantly from each other.

baseline information with which to compare development in culture. TH catalytic activity was initially detected at E13 in the nigra, which correlates with the appearance of this enzyme in other CA brain regions (Coyle, 1973; Rothman et al., 1980; Specht et al., 198 lb; Dreyfus et al., 1983). TH-immunoreactive protein was also first detected at this age, suggesting that the protein is initially expressed in a catalytically active form. To define potential environmental signals that regulate ontogeny subsequent to initial expression, the nigra was grown in an accessible, malleable tissue culture system.

\section{TH development in culture}

Explants of SN were dissected from the E15 embryo and maintained in vitro. TH was localized immunocytochemically to cells exhibiting morphological traits of dopaminergic neurons in vivo, including multipolarity, long, ramifying processes, and diameter of approximately $14 \mu \mathrm{m}$. Further, catecholamine fluorescence was detected in cells within the explant, suggesting that the TH was active enzymatically, synthesizing catecholamines in culture. After varying periods of time, cultures were assayed for TH catalytic activity to determine whether this trait developed in vitro. Strikingly, TH developed in culture, in the absence of many normal environmental signals present in vivo. However, TH did not achieve normal in vivo levels in culture, suggesting that some environmental cues were absent in basal cultures. One potentially important set of signals may derive from presynaptic innervation that is absent in culture. Ontogeny of TH in other neuronal populations is known to require transsynaptic stimulation (Black et al., 1971; Thoenen, 1974). Consequently, we used the explant culture system to examine the effect of depolarizing agents on the development of the dopaminergic phenotype in the SN.

\section{Effect of veratridine on $T H$ development}

To determine whether membrane depolarization may regulate development of TH in the nigra, explants were exposed to depolarizing agents. The pharmacologic agent veratridine elicited a significant elevation in TH activity. Veratridine evokes de- 

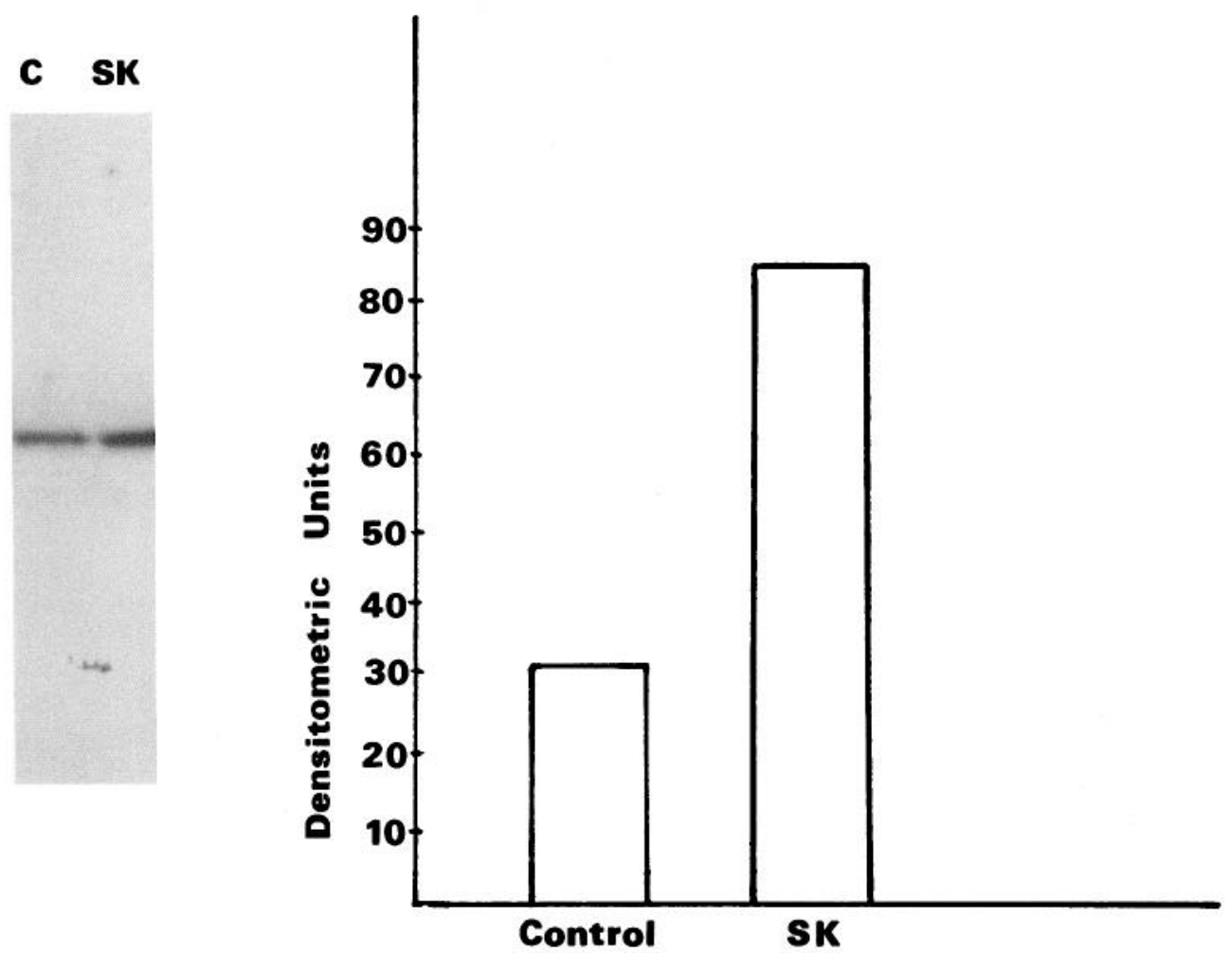

Figure 9. Western blot of E15 SN cultures grown for 1 week with or without $0.1 \mu \mathrm{M}$ substance K. $C$, control, $S K$, substance $\mathrm{K}$. TH was visualized using a specific antiserum followed by labeling with ${ }^{125} \mathrm{I}$-protein A. Densitometry is expressed in arbitrary units.

polarization by opening voltage-dependent sodium channels, allowing ion influx (Ohta et al., 1973; Couraud et al., 1986). Prevention of $\mathrm{Na}^{+}$influx with TTX blocked the veratridinestimulated rise of $\mathrm{TH}$ activity. Consequently, it appears that depolarization and/or sodium influx, regulates $\mathrm{TH}$ in central dopaminergic neurons, as in central noradrenergic neurons (Dreyfus et al., 1986).

To further investigate mechanisms underlying the veratridine-stimulated increase in $\mathrm{TH}$ activity, immunoblot analysis was performed. The immunoblot procedure allowed us to determine whether the rise in catalytic activity was associated with enzyme activation or with elevated levels of enzyme protein. Densitometric analysis of the immunoblots revealed that the depolarizing agent elicited an increase in enzyme protein concomitant with, and quantitatively indistinguishable from, the rise in enzyme activity. Consequently, the rise in $\mathrm{TH}$ activity appears entirely attributable to elevated levels of enzyme protein. Thus, depolarizing signals may lead to increased synthesis (or decreased degradation) of a critical neurotransmitter biosynthetic enzyme. These results are consistent with mechanisms underlying TH development in peripheral (Joh et al., 1973; Black et al., 1974; Hefti et al., 1982) and central (Dreyfus et al., 1986) noradrenergic neurons. More generally, depolarizing stimuli appear to influence development of diverse central and peripheral neurons.

\section{Effects of presynaptic agonists}

To begin defining the physiologic relevance of our observations, we examined the effects of normal presynaptic agonists on nigral development. One of the important excitatory afferents innervating the nigra contains the tachykinin peptides, SP and SK. We initially examined SP, a well-characterized neuropeptide. Indeed, exposure of cultures to a metabolically stable analog of SP elicited a significant increase in TH activity, mimicking the effects of veratridine. However, the rise evoked by SP was never as great as that elicited by veratridine. Moreover, previous work has indicated that SP binding is relatively low in the nigra, whereas SK binding sites are abundant (Shults et al., 1982, 1985; Quirion et al., 1983; Mantyh et al., 1984). Consequently, we examined the effects of SK in culture.

In all instances, SK increased nigral TH far greater than SP. TTX blocked the increase, suggesting that the SK-induced rise in $\mathrm{TH}$ was associated with $\mathrm{Na}^{+}$influx. Further, the increase in catalytic activity was associated with a parallel elevation of TH protein, determined by immunoblot analysis. We tentatively conclude that stimulation of SK receptors induces depolarization with attendant $\mathrm{Na}^{+}$influx, leading to elevation of $\mathrm{TH}$ molecule number and catalytic activity. While we have not definitively excluded the possibility that the varying treatments alter CA neuron survival, it appears unlikely that the very different agents employed all specifically enhance survival. Nevertheless, to address this alternative, it will be necessary to perform morphometric studies. One serious obstacle to such experiments is the lack of a totally independent marker of CA neurons. Since TH and other CA markers are directly altered by depolarization, it can be confounding to use these indices for morphometric investigation. We are presently attempting to define entirely independent criteria that will allow us to address this question.

In summary, different peptides, derived from the same precursor molecule, regulate a transmitter rate-limiting enzyme in postsynaptic neurons. It will be important to determine whether SP and SK exert synergistic effects and whether their actions involve homologous or heterologous receptor interactions. More generally, future work may indicate whether diverse polyproteins contain peptides that elicit closely related physiologic effects as part of the polyprotein strategy. It is also not yet clear whether the peptides act directly on the TH-containing neurons or indirectly via other neuronal or non-neuronal cells. Regard- 
less, our observations suggest that physiologic depolarizing stimuli regulate the development and function of $\mathrm{CA}$ neurons in the brain as in the periphery.

\section{References}

Anden, N. E., A. Dahlstrom, K. Fuxe, K. Larsson, L. Olson, and U. Ungerstedt (1966) Ascending monoamine neurons to the telencephalon and diencephalon. Acta Physiol. Scand. 67: 313-326.

Berger, B., U. DiPorzio, M. C. Daguet, M. Gay, A. Vigny, J. Glowinski, and A. Prochiantz (1982) Long-term development of mesencephalic dopaminergic neurons of mousc cmbryos in dissociatcd primary cultures: Morphological and histochemical characteristics. Neuroscience 7: 193-205.

Berod, A., B. K. Hartman, and J. F. Pujol (1981) Importance of fixation in immunohistochemistry: Use of formaldehyde solutions at variable $\mathrm{pH}$ for the localization of tyrosine hydroxylase. J. Histochem. Cytochem. 29: 844-850.

Black, I. B. (1975) Increased tyrosine hydroxylase activity in frontal cortex and cerebellum after reserpine. Brain Res. 95: 170-176.

Black, I. B. (1978) Regulation of autonomic development. Annu. Rev. Neurosci. 1: 183-214.

Black, I. B., and P. H. Patterson (1980) Developmental regulation of neurotransmitter phenotype. Curr. Top. Dev. Neurobiol. 15: 27-39.

Black, I. B., I. A. Hendry, and L. L. Iversen (1971) Transsynaptic rcgulation of growth and development of adrenergic neurons in a mouse sympathetic ganglion. Brain Res. 34: 229-240.

Black, I. B., T. H. Joh, and D. J. Reis (1974) Accumulation of tyrosine hydroxylase molecules during growth and development of the superior cervical ganglion. Brain Res. 75: 133-144.

Bohn, M. C. (1983) Role of glucocorticoids in expression and development of phenylethanolamine- $\mathrm{N}$-methyltransferase (PNMT) in cells derived from the neural crest: A review. Psychoneuroendocrinology 8: $381-390$.

Bornstein, M. B. (1973) Organotypic mammalian central and peripheral nerve tissue. In Tissue Culture Methods and Applications, P. F. Kruse and M. K. Patterson, eds., pp. 86-92, Academic, New York.

Bradford, M. M. (1976) A rapid and sensitive method for quantification of microgram quantities of protein utilizing the principle of protein dye-binding. Anal. Biochem. 72: 248-254.

Couraud, F., N. Martin-Moutot, A. Koulakoff, and Y. Berwald-Netter (1986) Neurotoxin-sensitive sodium channels in neurons developing in vivo and in vitro. J. Neurosci. 6: 192-198.

Coyle, J. T. (1973) Development of the central catecholaminergic neurons of the rat. In Frontiers in Catecholamine Research, E. Usdin and S. Snyder, eds., pp. 261-265, Pergamon, New York.

Coyle, J. T., and J. Axelrod (1972) Tyrosine hydroxylase in rat brain: Developmental characteristics. J. Neurochem. 19: 1117-1123.

Coyle, J. T., D. Jacobowitz, D. Klein, and J. Axelrod (1973) Dopaminergic neurons in explants of substantia nigra in culture. J. Neurobiol. 4: 461-470.

Dibner, M. D., and I. B. Black (1976) The effect of target organ removal on the development of sympathetic neurons. Brain Res. 103:93-102.

Doupc, A. J., S. C. Landis, and P. H. Patterson (1985) Environmental influences in the development of neural crest derivatives: Glucocorticoids, growth factors, and chromaffin cell plasticity. J. Neurosci. 5: 2119-2142.

Dreyfus, C. F., M. D. Gershon, and S. M. Crain (1979) Innervation of hippocampal explants by central catecholaminergic neurons in cocultures fetal mouse brainstem explants. Brain Res. 161: 431-445.

Dreyfus, C. F., E. R. Peterson, and S. M. Crain (1980) Failure of nerve growth factor to affect fetal mouse brainstem catecholaminergic neurons in culture. Brain Res. 194: 540-547.

Dreyfus, C. F., K. A. Markey, M. Goldstein, and I. B. Black (1983) Development of catecholaminergic phenotypic characters in the mouse locus coeruleus in vivo and in culture. Dev. Biol. 97: 48-58.

Dreyfus, C. F., W. J. Friedman, K. A. Markey, and I. B. Black (1986) Depolarizing stimuli increase tyrosine hydroxylase in the mouse locus coeruleus in culture. Brain Res. 379: 216-222.

Fallon, J. H., J. N. Riley, and R. Y. Moore (1978) Substantia nigra dopamine neurons: Separate populations project to neostriatum and allocortex. Neurosci. Lett. 7: 157-162.

Feldman, L. T., M. J. Imperiale, and J. R. Nevins (1982) Activation of early adenovirus transcription by the herpes immediate early gene: Evidence for a common cellular control factor. Proc. Natl. Acad. Sci. USA 79: 4952-4956.
Fuxe, K., T. Hökfelt, D. Johansson, P. Jonsson, P. Lidbrink, and A. Ljungdahl (1974) The origin of the dopamine nerve terminals in limbic and frontal cortex. Evidence for mesocortical dopamine neurons. Brain Res. 82: 349-355.

Hefti, F., H. Gnahn, M. E. Schwab, and H. Thoenen (1982) Induction of tyrosine hydroxylase by nerve growth factor and by elevated $\mathrm{K}^{+}$ concentrations in cultures of dissociated sympathetic neurons. J. Neurosci. 2: 1554-1556.

Innis, R. B., R. Androde, and G. K. Aghajanian (1985) Substance K excites dopaminergic and non-dopaminergic neurons in rat substantia nigra. Brain Res. 335: 381-383.

Joh, T. H., C. Geghman, and D. Reis (1973) Immunochemical demonstration of increased accumulation of tyrosine hydroxylase protein in sympathetic ganglia and adrenal medulla elicited by reserpine. Proc. Natl. Acad. Sci. USA 70: 2767-2771.

Kao, C. Y. (1966) Tetrodotoxin, saxitoxin and their significance in the study of excitation phenomena. Pharmacol. Rev, 18: 997-1049.

Kotake, C., P. C. Hoffman, and A. Heller (1982) The biochemical and morphological development of differentiating dopamine neurons coaggregated with their target cells of the corpus striatum in vitro. J. Neurosci. 2: 1307-1315.

Lauder, J. M., and F. E. Bloom (1974) Ontogeny of monoamine neurons in the locus coeruleus, raphe nuclei and substantia nigra of the rat. 1. Cell differentiation. J. Comp. Neurol. 155: 469-482.

Levitt, M., S. Spector, A. Sjoerdsma, and S. Udenfriend (1965) Elucidation of the rate-limiting stcp in norepinephrine biosynthesis in the perfused guinea pig heart. J. Pharmacol. Exp. Ther. 148: 1-8.

Mantyh, P. W., J. E. Maggio, and S. P. Hunt (1984) The autoradiographic distribution of kassinin and substance $\mathrm{K}$ binding sites is different from the distribution of substance $P$ binding sites in rat brain. Eur. J. Pharmacol. 102: 361-364.

Markey, K. A., S. Kondo, L. Shenkman, and M. Goldstein (1980) Purification and characterization of tyrosine hydroxylase from a clonal pheochromocytoma cell line. Mol. Pharmacol. 17: 79-85.

Masurovsky, E. B., and E. R. Peterson (1973) Photoreconstituted collagen gel for tissue culture substrates. Exp. Cell Res. 76: 447-448.

Nawa, H., H. Kotani, and S. Nakanishi (1984a) Tissue-specific generation of two preprotachykinin mRNAs from one gene by alternative RNA splicing. Nature 312: 729-734.

Nawa, H., M. Doteuchi, K. Igano, K. Inouye, and S. Nakanishi (1984b) Substance K: A novel mammalian tachykinin that differs from substance $\mathrm{P}$ in its pharmacological profile. Life Sci. 34: 1153-1160.

Ohta, M., T. Narahashi, and R. Keeler (1973) Effects of veratrum alkaloids on membrane potential and conductance of squid and crayfish giant axons. J. Pharmacol. Exp. Ther. 184: 143-154.

Olson, L., and A. Seiger (1972) Early prenatal ontogeny of central monoamine neurons in the rat: Fluorescence histochemical observations. Z. Anat. Entwick. Gesch. 137: 301-316.

Patterson, P. H. (1978) Environmental determination of autonomic neurotransmitter functions. Annu. Rev. Neurosci. 1: 1-17.

Quirion, R., C. W. Shults, T. W. Moody, C. B. Pert, T. N. Chase, and T. L. O'Donohue (1983) Autoradiographic distribution of substance $P$ receptors in rat central nervous system. Nature 303: 714-716.

Rothman, T. P., L. A. Specht, M. D. Gershon, T. H. Joh, G. Teitelman, V. M. Pickel, and D. J. Reis (1980) Catecholamine biosynthetic enzymes are expressed in replicating cells of the peripheral but not the central nervous system. Proc. Natl. Acad. Sci. USA 77: 62216225 .

Schlumpf, M., W. J. Shoemaker, and F. E. Bloom (1977) Explant cultures of catecholamine-containing neurons from rat brain: Biochemical, histofluorescence and electron microscopic studies. Proc. Natl. Acad. Sci. USA 74: 4471-4475.

Shults, C. W., R. Quirion, R. T. Jensen, T. W. Moody, and T. N. Chase (1982) Autoradiographic localization of substance $P$ receptors using ${ }^{125}$ I substance P. Peptides 3: 1073-1075.

Shults, C. W., H. Yajima, H.-G. Gullner, T. N. Chase, and T. L. O'Donohue (1985) Demonstration and distribution of kassinin-like material (substance K) in the rat central nervous system. J. Neurochem. 45: 552-558.

Specht, L. A., V. M. Pickel, T. H. Joh, and D. J. Reis (1981a) Fine structure of the nigrostriatal anlage in fetal rat brain by immunocytochemical localization of tyrosine hydroxylase. Brain Res. 218: 4965.

Specht, L. A., V. M. Pickel, T. H. Joh, and D. J. Reis (1981b) Lightmicroscopic immunocytochemical localization of tyrosine hydrox- 
ylase in prenatal rat brain. I. Early ontogeny. J. Comp. Ncurol. 199: 233-253.

Specht, L. A., V. M. Pickel, T. H. Joh, and D. J. Reis (1981c) Lightmicroscopic immunocytochemical localization of tyrosine hydroxylase in prenatal rat brain. II. Late ontogeny. J. Comp. Neurol. 199: 255-276.

Thoenen, H. (1974) Trans-synaptic enzyme induction. Life Sci. 14: 223-235.

Towbin, H., T. Staehelin, and J. Gordon (1979) Electrophoretic transfer of proteins from polyacrylamide gels to nitrocellular sheets: Procedure and some applications. Proc. Natl. Acad. Sci. USA 76:43504354.
Udenfriend, S. (1966) Tyrosine hydroxylase. Pharmacol. Rev. 18:4351.

Verney, C., B. Berger, J. Adrien, A. Vigny, and M. Gay (1982) Development of the dopaminergic innervation of the rat cerebral cortex. A light microscopic study using anti-tyrosine hydroxylase antibodies. Dev. Brain Res. 5: 41-52.

Walicke, P. A., R. B. Campenot, and P. H. Patterson (1977) Determination of transmitter function by neuronal activity. Proc. Natl. Acad. Sci. USA 74: 5767. 